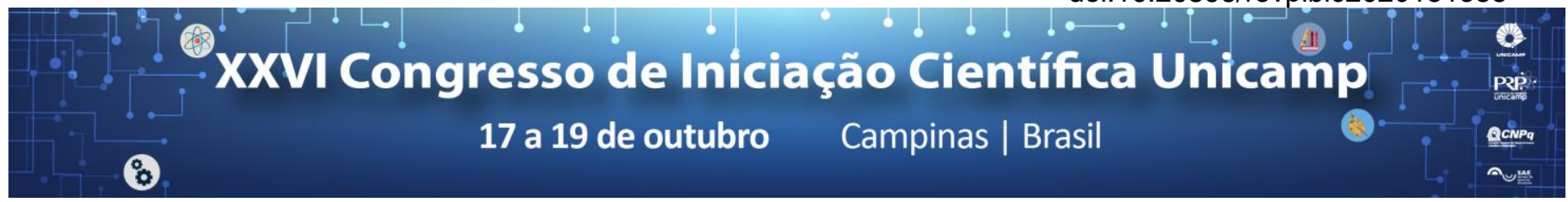

\title{
Development of an interface using Augmented Reality for public transport users
}

\section{Wilson A. Sedano Filho*, Maria T. Françoso}

\begin{abstract}
In Brazil, there is no academic production regarding the Augmented Reality focused on the transportation field. It is noted that this area is highly studied in the scope of digital games, architecture and urbanism. The principal objective of this research is the development of an interface adapted to the Brazilian context which can be used by public transport users. This application aims to provide urban public transport passengers with information about lines, such as itineraries and schedules, with the purpose of facilitating the displacement, in addition to expanding the options of transportation within a city.
\end{abstract}

\section{Key words:}

Augmented Reality, Public Transport, Urban Planning

\section{Introduction}

The first stage of this research was the realization of a bibliographic review focused mainly on the concepts of Augmented Reality (AR), taking into account historical definitions, fundamental and distinctive parameters of this technology.

In a second step, an overview about the use of Augmented Reality was made, highlighting the areas of knowledge that use this artifice. The use of this technology in the field of urban public transport has also been analyzed.

Then, since the use of Augmented Reality applied to transport is not fully developed, a prototype of its application was created in small scale for the city of Campinas: a case study was conducted to use RA to meet the needs of the Viracopos Airport employees who use public transportation.

For this, in order to know the modes of transport used, a questionnaire has been applied. From their answers, we could model the application and create a database for the development of the tool.

\section{Results and Discussion}

In order to develop the application, we used a Google tool called MyMaps. From there, the developer can create maps through a simple interface in which points or shapes can be added (Image 1). We can also find places, create maps based on spreadsheets and include photos and videos at any point. In addition, maps created by the developer can be included in websites.

After developing the custom map using the MyMaps tool, it was necessary to export the content to the Keyhole Markup Language (KML) format. $\mathrm{KML}$ is a file format used to display geographic data in a browser. To do so, this format uses a tag structure with nested elements and attributes based on the XML (eXtensible Markup Language) standard.

The Wikitude application allows the user to create a "world". In a world, the developer can add everything the application will contain. In the case under study, as the points of interest have already been added to the custom map, it was necessary to import the $\mathrm{KML}$ document into the application.

Once this step is complete, the application is up and running and is available in the Wikitude application.

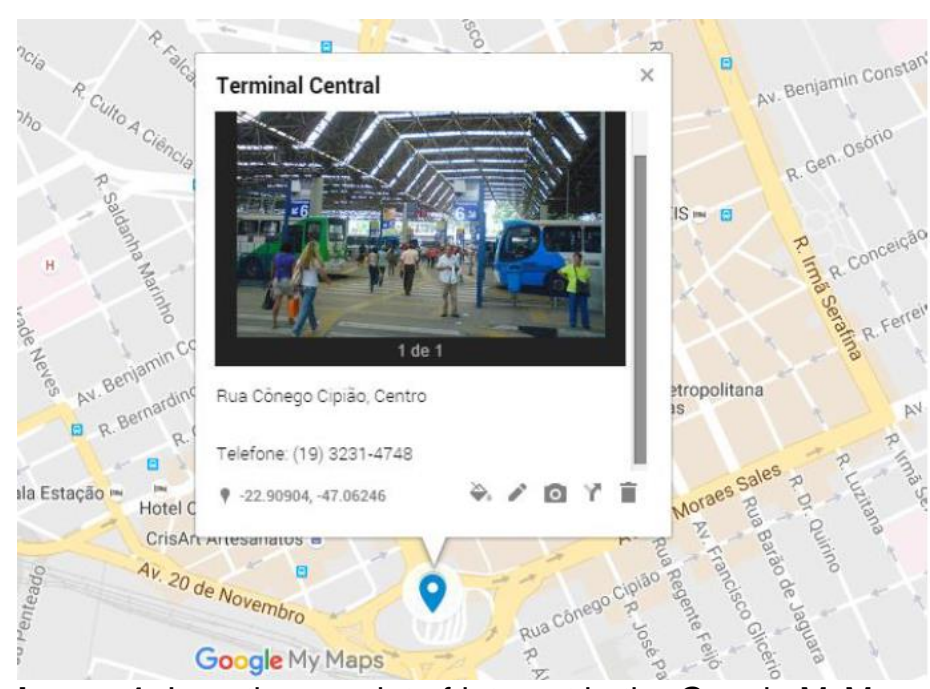

Image 1. Inserting a point of interest in the Google MyMaps tool

\section{Conclusions}

After finalizing the development of the application, it was possible to create a methodology of insertion of geographic data that concerns the field of transport in a tool that uses the Augmented Reality.

It is also hoped that the development of this type of application may become popular in the country, since these experiences are still very incipient in Brazil, especially in the area of transportation.

In addition, this application opens space for future developments of other tools in the city making use of Augmented Reality technology, with the aim of improving the quality of life.

\section{Acknowledgement}

This research was supported by the National Council for Scientific and Technological Development - CNPq. 